\title{
No association between MRI changes in the lumbar spine and intensity of pain, quality of life, depressive and anxiety symptoms in patients with low back pain
}

\author{
Anna Babińska ${ }^{1}$, Wojciech Wawrzynek ${ }^{1}$, Elżbieta Czech ${ }^{2}$, \\ Jarosław Skupiński ${ }^{1}$, Jarosław Szczygieł ${ }^{3}$, Beata Łabuz-Roszak ${ }^{4}$ \\ ${ }^{1}$ Department of Radiology, District Hospital of Orthopaedics and Trauma Surgery, Piekary Slaskie, Poland \\ ${ }^{2}$ Department of Biostatistics, Faculty of Public Health in Bytom, Medical University of Silesia, Katowice, Poland \\ ${ }^{3} 1$ st Department of Neurological Rehabilitation, Upper Silesian Rehabilitation Centre "Repty", Tarnowskie Gory, Poland \\ ${ }^{4}$ Department of Basic Medical Sciences, Faculty of Public Health, Medical University of Silesia, Katowice, Poland
}

\begin{abstract}
Introduction. The association between changes in magnetic resonance imaging (MRI) and clinical symptoms in patients with low back pain (LBP) is unclear.

Aim. To evaluate correlations between combined MRI findings of the lumbar spine (LS) and pain intensity, depressive and anxiety symptoms and quality of life in patients with LBP.

Material and methods. 200 subjects (93 men and 107 women; mean age $51.42 \pm 13.21$ years) with LBP referred for MRI were enrolled in the study. All patients completed the Hospital Anxiety and Depression Scale (HADS), Quality of Life Scales (EQ-5D, EQ-VAS) and the Visual Analogue Scale (VAS). MRI scans were assessed according to a scoring system prepared by the authors, and the total MRI score was calculated.

Results. The mean total MRI score was $11.59 \pm 6.73$ points (range $0-50$ points) and was higher in men than in women ( $p=0.015)$. A correlation was observed between total MRI score and age $(p<0.001)$ and between total MRI score and BMI $(p=0.005)$. An association was found between total MRI score and EQ-5D $(p=0.012)$ and HADS-D results $(p=0.003)$. VAS and HADS-A results did not correlate with MRI score. When multivariate analysis was done, the total MRI score was only significantly related to age and BMI, and association between the total MRI score and EQ-5D or HADS-D results was not confirmed. Decreased quality of life was associated with increased intensity of pain and depressive and anxiety symptoms.

Conclusions. Combined MRI changes in LS do not correlate with pain intensity, depressive and anxiety syndromes or quality of life in patients with LBP.
\end{abstract}

Key words: low back pain, quality of life, depressive symptoms, anxiety, MRI examination (Neurol Neurochir Pol 2019; 53 (1): 74-82)

\section{Introduction}

Low back pain (LBP) is an important and common public health problem which can lead to chronic pain syndromes and physical disability. It has also crucial socioeconomic implications due to the costs of diagnostic and therapeutic procedures, absence from work, and earlier retirement and pension [1]. Patients have sought medical help from general practitioners and specialists for many years. The consequences of chronic spinal pain such as physical disability, reduction

Address for correspondence: Anna Babińska, Department of Radiology, District Hospital of Orthopaedics and Trauma Surgery,

e-mail: annababinska88@gmail.com 
in professional efficiency and social disruption have negative impacts on quality of life in patients and can cause depressive and anxiety symptoms, affecting social relationships and family life [2-3].

While magnetic resonance imaging (MRI) is a sensitive diagnostic tool in patients with LBP, any associations between radiological findings of the lumbar spine (LS) and clinical symptoms remain controversial [4]. MRI is a nonspecific examination that reveals changes which often correlate poorly with clinical manifestations. Some authors have found a higher prevalence of spinal abnormalities in MRI in asymptomatic patients [5-7]. Disc herniation, disc degeneration, Modic type endplate changes and annular tears are common findings in LS MRI in patients with LBP, and also in asymptomatic patients since such changes may be due to the ageing process of the spine.

Although numerous studies have investigated the relationship between pain intensity and particular MRI abnormalities $[4,8,9]$, it is still unclear how combined MRI can influence clinical symptoms. According to Chou et al. [10], patients with severe back pain tend to have a higher prevalence of the degenerative changes found in MRI. Previous studies [11-13] have focused on looking for an association between the combined MRI findings and clinical outcomes, comparing the degree of disability and pain intensity with the total number of radiological abnormalities. Similarly, in our study we considered extensive MRI changes in the LS in patients with LBP. However, unlike the above studies, we focused on different clinical and radiological aspects. We analysed whether the combined MRI changes in the LS (from L1 to S1 levels) were related to pain intensity, depressive and anxiety syndromes and quality of life. Previous studies have found no clear association between MRI findings and the degree of disability or pain. Additionally, associations between radiological changes and depression, anxiety and quality of life have been unclear [11-13].

\section{Aim}

The aim of our study was to evaluate the correlations between combined MRI findings in the LS and pain intensity, depressive and anxiety symptoms and quality of life in patients with LBP.

\section{Material and methods}

This study was conducted between May 2015 and December 2017. Patients with LBP referred for LS MRI were enrolled in the study.

According to the Bioethics Committee, the study was not a medical experiment. Therefore, no approval of the Committee was required. All patients provided informed written consent prior to study enrollment.

All participants were referred for MRI examination by orthopaedic surgeons, neurosurgeons, neurologists or general surgeons. In total, 200 patients met the following inclusion criteria: current or previous history of LBP, and age $\geq 18$ years old. The exclusion criteria were as follows: previous surgery or interventional LS procedures, suspected or previous evidence of neoplasm or discitis, prior or active fractures of lumbar vertebrae, history of acute trauma to the lower back, structural vertebral changes (e.g. spondylolysis, spondylolisthesis, ankylosis, vertebral deformity), mild cognitive impairment, dementia or other mental illness. A Mini-Mental State Examination (MMSE) was performed to exclude patients with cognitive impairment. Eligible patients were requested to participate in the study.

Each subject was interviewed using a questionnaire prepared by the authors of the study. This questionnaire included questions related to the age, symptoms, education, professional activity, marital status, physical activity and socioeconomic status of the subjects. Neurological examination was performed by one of the authors of the study. The following questionnaires were used in the study: the Hospital Anxiety and Depression Scale (HADS), the Visual Analogue Scale (VAS) and Quality of Life Scales (EQ-5D, EQ-VAS). Medical history was obtained, physical examination was performed, and the questionnaires were completed prior to MRI examination.

\section{Pain assessment}

Intensity of pain was assessed using the Visual Analogue Scale (VAS). This scale determines pain intensity from 0 to 10 with the use of a $10 \mathrm{~cm}$ ruler where 0 means no pain, and 10 the worst pain imaginable [14].

\section{Depressive and anxiety symptoms}

Depressive and anxiety symptoms were assessed by the Hospital Anxiety and Depression Scale (HADS) which is a self-assessment screening questionnaire [15]. Patients were asked to select one response from four options for each question.

The questions related to anxiety marked with "A“ (7 questions - HADS-A) and to depression marked with „D“ (7 questions - HADS-D) were given alternately. The scores (from 0 to 3) for each question for "A" and separately for " $D$ " were added together to obtain two results i.e. for anxiety and depression. A total score from 0 to 7 indicates no abnormality, $8-10$ is borderline, and 11 and above suggests anxiety or depression.

\section{Quality of life}

Quality of life was assessed using a EuroQol 5D quality of life self-esteem questionnaire, which consists of two parts i.e. the EQ-5D and EQ-VAS. The EQ-5D covers five dimensions: mobility, self-care, usual activities, pain/discomfort, and anxiety/depression. Three responses to each question are possible. For the purposes of our study, the following scoring system was established: from 1 (no problem) to 
3 points (considerable problems) for each question, and then the sum was calculated, giving a possible maximum score of 15 (i.e. the worst health status). The Polish validated version of the questionnaire was used [16]. A permission EuroQol Research Foundation was obtained to use it.

EQ-VAS is an analogue visual scale assessing general health status and disease activity from 0 (the worst imaginable health) to 100 (the best possible health). Most often it is presented as a vertical $100 \mathrm{~mm}$-long line on which patients mark a horizontal line corresponding to their own judgment of disease severity. The result is obtained by measuring (in millimetres) the distance from the beginning of the scale to the place selected by the patient.

\section{Magnetic resonance imaging}

MR scans were performed using 3 T MR GE DISCOVERY 750W (57 patients) and 1.5 T ESPREE SIEMENS MR (143 patients). The following sequences of the LS (from L1 to S1 levels) were applied: sagittal T2-weighted images, sagittal T1-weighted images, sagittal T2-proton density weighted images, coronal T2-weighted images, and axial T2-weighted images angled parallel to individual disc spaces at each level between L1-S1. Slice thickness for 1.5T magnets was $4.0 \mathrm{~mm}$ with a $0.4 \mathrm{~mm}$ gap, the field of view (FOV) was $160 \mathrm{~mm}$ (axial T2) and $320 \mathrm{~mm}$ (other sequences); slice thickness for 3T magnets was between 3.0 and $4.0 \mathrm{~mm}$ with a $0.3-0.5 \mathrm{~mm}$ gap, FOV was $200 \mathrm{~mm}$ (axial $\mathrm{T} 2$ ) and $340 \mathrm{~mm}$ (other sequences).

Each MR examination was assessed by two radiologists independently, according to the protocol previously defined by the authors and classified for the presence or absence of the following abnormalities at each disc level of the LS: disc herniation, disc degeneration (according to the Pfirrmann scale), Modic type endplate changes, annular tears and nerve impingements (Fig. 1). If there was a disparity between assessments, a third independent radiological assessment was made and a consensus was reached. Prior to the analysis, a scoring system for the selected MRI findings was established (Tab. 1).

Disc herniation was classified as normal, 'bulging', protrusion, extrusion or sequestration (Fig. 2). We decided to rate 'bulging' lower than protrusion, extrusion and sequestration based on the recommendations proposed by
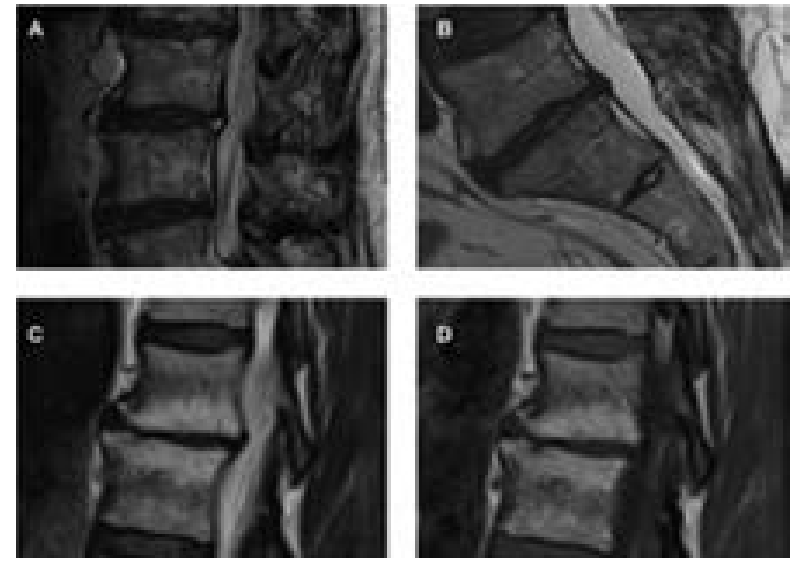

Figure 1. Examples of MRI findings evaluated in the study: A) HIZ and B) disc degeneration grade 5, according to the Pfirrmann scale on sagittal T2-weighted image; C) and D) Modic type 2 endplate changes on sagittal T2- and T1-weighted images
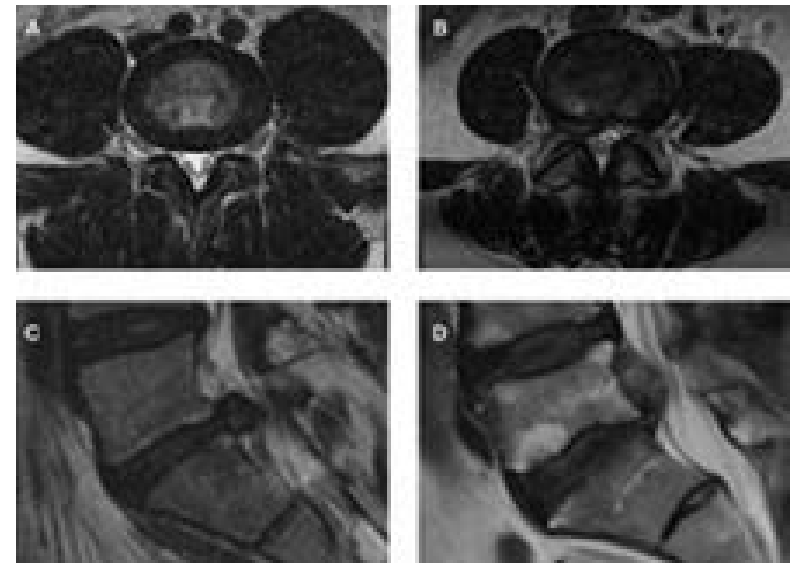

Figure 2. Typical features of lumbar disc pathology on T2-weighted images: A) disc bulge, B) protrusion, C) extrusion, and D) sequestration

Fardon et al. [17] that classified it not as a herniation, but rather as the first step in symmetric disc degeneration. Disc degeneration was assessed on sagittal T2-weighted images using a five-level grading system proposed by Pfirrmann which evaluates signal intensity changes in a disc, its internal

Table 1. MRI scoring system

\begin{tabular}{|c|c|c|c|}
\hline Radiological finding & 0 points & 1 point & 2 points \\
\hline Disc herniation & Normal & Bulging & Protrusion, extrusion, sequestration \\
\hline $\begin{array}{l}\text { Disc degeneration according to the } \\
\text { Pfirrmann scale }\end{array}$ & Grade 1 & Grades 2 and 3 & Grades 4 and 5 \\
\hline Modic type endplate changes & Type 0 & Types 2 and 3 & Type 1 \\
\hline Annular tears & Absent & - & Present \\
\hline Nerve root/spinal nerve & Normal & Displacement & Compression \\
\hline
\end{tabular}


structure, homogeneity and height [18]. Grade 1 was scored at 0 points as this represents the appearance of a regular disc. Modic type signal intensity changes in an adjacent endplate vertebral body were classified according to the scale as type 1: T1 hypointense and T2 hyperintense signal, type 2: T1 and T2 hyperintense signal, type 3: T1 and T2 hypointense signal intensity and type 0 : no changes [19]. In this study, type 1 was rated higher than types 2 and 3 . The most recent reports have indicated a significant relationship between pain intensity in patients with LBP and Modic changes type 1 [20-22]. According to other researches, types 2 and 3 did not show this relationship. Annular tear was defined as a high-signal intensity zone (HIZ) on T2-weighted images in the posterior part of the disc that was brighter than the nucleus pulposus. Posterior HIZ was rated as either present or absent. There is no transitional form for this finding, therefore it was scored at either 0 or 2 points. Nerve root changes were assessed as normal, displaced, or compressed.

The MRI scoring system ranged from 0 to 50 points. The maximum number of points was 10 for each intervertebral space level of the LS. The sum of all points at disc levels from L1 to S1 gave us the number (the total MRI score) which represented the severity of LS degeneration assessed in MRI.

\section{Statistical analysis}

Statistical analysis was performed using STATISTICA 12, Stat Soft Poland and R 3.3.2, GNU General Public License. Data were expressed as the mean with standard deviation and median (minimum $\div$ maximum) and as the number and percentage. The following tests were used: the chi-square Pearson, Kruskal-Wallis, t-Student, U Mann-Whitney, multivariate analysis - general linear regression model (GLM). The Spearman's Rho correlation analysis was also performed. A p-value of $<0.05$ was considered significant.

\section{Results}

The study comprised 200 patients (93 men and 107 women, mean age $51.42 \pm 13.21$ years). The average back pain duration was 66.68 (SD 78.92) months. The patient characteristics are presented in Table 2.

Neurological examination revealed unilateral or bilateral abnormalities (symptoms of irritation or damage to nerve roots) in 76 patients (38\%). Stretching symptoms (Laseque sign) were present in 70 subjects $(35 \%)$, nerve root sensory disorders in 18 (9\%), distal muscle weakness in 13 (6.5\%), (limited plantar or dorsal flexion of the foot) and absent knee or Achilles tendon reflexes were found in 15 patients (7.5\%). Only one patient reported sphincter disorders. Local symptoms related to LS (increased paraspinal muscle tone and/ or limitation of spinal mobility and/or pain on palpation of spinous processes and/or reactive scoliosis) were present in 126 cases $(63 \%)$. Neurological examination revealed no other central or peripheral changes.
Abnormalities in neurological examinations correlated with MRI findings. Nerve root compression and/or severe or moderate spinal stenosis at any spinal level were seen on MRI scans in all patients with the symptoms of root damage in neurological examinations. Only six patients $(8.6 \%)$ of all subjects with stretching symptoms had no nerve root changes related to the L1-S1 levels.

The results of the questionnaires are presented in Table 3. Analysis of the results between both genders showed only statistically significant higher results (but still within the range) of HADS-A in women compared to men ( $p=0.046$ ). The results of HADS-D, EQ-5D and EQ-VAS were statistically significantly associated with the age of patients $(p<0.001$, $\mathrm{p}=0.024, \mathrm{p}=0.001$, respectively) and the BMI ( $\mathrm{p}=0.005$, $\mathrm{p}<0.001, \mathrm{p}<0.001$, respectively). The VAS scale results related only to the BMI $(\mathrm{p}=0.014)$. The results of EQ-5D correlated with the results of the VAS scale $(\mathrm{p}<0.001, \mathrm{R}=0.47)$, HADS-A $(\mathrm{p}<0.001, \mathrm{R}=0.44)$ and HADS-D $(\mathrm{p}<0.001, \mathrm{R}=0.55)$, which meant that a decrease in quality of life in patients was associated with a higher intensity of back pain and depressive and anxiety symptoms.

The mean total MRI score was $11.59 \pm 6.73$ points, with a statistically significant difference between women and men $(10.47 \pm 6.46$ and $12.88 \pm 6.83$ points, respectively; $\mathrm{p}=0.015)$ (Tab. 4). Most of the radiological changes were related to the L4-L5 and L5-S1 levels. Correlations were found between the total MRI score and the age of patients $(\mathrm{p}<0.001, \mathrm{R}=0.55)$ and BMI ( $\mathrm{p}=0.005, \mathrm{R}=0.2)$. The most common radiological finding in the study group was a disc bulge, and the least common was sequestration, which was observed only three times (Tab. 5).

The mean waiting time for MRI was $7.49 \pm 5.81(0 \div 31)$ months. The mean number of LS radiographs was $1.77 \pm$ $1.75(0 \div 10)$, CTs $-0.83 \pm 0.99(0 \div 6)$ and MRIs $-0.85 \pm 0.96$ $(0 \div 4)$ of LS (done during the whole life by subjects).

An association was found between the total MRI score and EQ-5D results $(\mathrm{R}=0.18, \mathrm{p}=0.012)$ as well as HADS-D results $(\mathrm{R}=0.21, \mathrm{p}=0.003)$. The results of other questionnaires (VAS, HADS-A) did not correlate with the total MRI score (Tab. 6). But when multivariate analysis was done (with variables significantly related to the total MRI score: age, gender, BMI, EQ-5D score, HADS-D score), significant associations were only found for the total MRI score and age $(\mathrm{p}<0.001)$, and the total MRI score and BMI $(\mathrm{p}<0.001)$. Multivariate analysis did not confirm an association between the total MRI and EQ-5D scores, as well as between the total MRI and HADS-D scores observed in univariate analyses.

Being professionally active was related to decreased pain intensity $(p=0.002)$, lower scores in HADS-D $(p=0.002)$ and better quality of life ( $p=0.002$ for EQ5D, $p=0.003$ for EQ-VAS; U Mann-Whitney test). Unlimited physical activity was also associated with decreased pain intensity $(\mathrm{p}<0.001)$, lower scores in HADS-D $(\mathrm{p}<0.001)$ and HADS-A $(\mathrm{p}<0.001)$ and better quality of life $(\mathrm{p}<0.001$ for EQ5D and EQ-VAS; 
Table 2. Patient characteristics

\begin{tabular}{|c|c|c|c|c|c|}
\hline & & $\begin{array}{l}\text { Women } \\
N=107\end{array}$ & $\begin{array}{c}\text { Men } \\
\mathrm{N}=93\end{array}$ & $\begin{array}{l}\text { All subjects } \\
\qquad \mathbf{N}=\mathbf{2 0 0}\end{array}$ & $\begin{array}{c}\text { P } \\
\text { women vs men }\end{array}$ \\
\hline \multirow[t]{2}{*}{ Age (years)* } & & $51.08 \pm 12.68$ & $51.82 \pm 13.86$ & $51.42 \pm 13.21$ & \multirow{2}{*}{$p=0.949 U$} \\
\hline & & $54.0(20 \div 75)$ & $52.5(21 \div 80)$ & $54.0(20 \div 80)$ & \\
\hline \multirow[t]{2}{*}{$\operatorname{BMI}\left(\mathrm{kg} / \mathrm{m}^{2}\right)^{*}$} & & $27.01 \pm 4.47$ & $27.99 \pm 4.26$ & $27.13 \pm 4.89$ & \multirow{2}{*}{$p=0.117 t$} \\
\hline & & $26.9(17.1 \div 40.9)$ & $27.8(18.6 \div 41.6)$ & $26.9(18.6 \div 41.6)$ & \\
\hline \multirow[t]{3}{*}{ Education** } & Elementary & $30(28.0 \%)$ & $25(26.9 \%)$ & $55(27.5 \%)$ & \multirow{3}{*}{$p=0.206 x$} \\
\hline & Secondary & $41(38.3 \%)$ & $46(49.5 \%)$ & $87(43.5 \%)$ & \\
\hline & University & $36(33.7 \%)$ & $22(23.6 \%)$ & $58(29.0 \%)$ & \\
\hline \multirow[t]{2}{*}{ Marital status** } & Married/in a partnership & $71(66.4 \%)$ & $74(79.6 \%)$ & $145(72.5 \%)$ & \multirow[b]{2}{*}{$p=0.037 x$} \\
\hline & $\begin{array}{l}\text { Single/divorced/ } \\
\text { /widow/widower }\end{array}$ & $36(33.6 \%)$ & $19(20.4 \%)$ & $55(27.5 \%)$ & \\
\hline \multirow{3}{*}{$\begin{array}{l}\text { Place of residence }{ }^{* *} \\
\mathrm{~N}=196 \\
\text { (no data in four subjects) }\end{array}$} & Village & $20(19.0 \%)$ & $21(23.0 \%)$ & $41(20.9 \%)$ & \multirow{3}{*}{$p=0.678 x$} \\
\hline & Town $<100,000$ inhabitants & $51(48.6 \%)$ & $45(49.5 \%)$ & $96(49.0 \%)$ & \\
\hline & City $>100,000$ inhabitants & $34(32.4 \%)$ & $25(27.5 \%)$ & $59(30.1 \%)$ & \\
\hline \multirow{2}{*}{$\begin{array}{l}\text { Professional activity** } \\
\mathrm{N}=196 \\
\text { (no data in four subjects) }\end{array}$} & Active & $57(54.8 \%)$ & $49(53.3 \%)$ & $106(54.1 \%)$ & \multirow[b]{2}{*}{$p=0.828 x$} \\
\hline & Inactive & $47(45.2 \%)$ & $43(46.7 \%)$ & $90(45.9 \%)$ & \\
\hline \multirow[t]{3}{*}{ Physical activity** } & Without problems & $43(40.2 \%)$ & $32(34.4 \%)$ & $75(37.5 \%)$ & \multirow{3}{*}{$p=0.127 F$} \\
\hline & $\begin{array}{l}\text { Some movement-related } \\
\text { problems }\end{array}$ & $62(57.9 \%)$ & $54(58.1 \%)$ & $116(58 \%)$ & \\
\hline & $\begin{array}{l}\text { Unable to walk without } \\
\text { help }\end{array}$ & $2(1.9 \%)$ & $7(7.5 \%)$ & $9(4.5 \%)$ & \\
\hline \multirow{5}{*}{$\begin{array}{l}\text { Socioeconomic status** } \\
\mathrm{N}=189 \\
\text { (no data in } 11 \text { subjects) }\end{array}$} & Very good & $9(8.9 \%)$ & $5(5.7 \%)$ & $14(7.4 \%)$ & \multirow{5}{*}{$p=0.029 F$} \\
\hline & Good & 35 (34.7\%) & 42 (47.7\%) & 77 (40.7\%) & \\
\hline & Average & 48 (47.5\%) & $40(45.5 \%)$ & $88(46.6 \%)$ & \\
\hline & Bad & 0 & 0 & 0 & \\
\hline & No opinion & $9(8.9 \%)$ & $1(1.1 \%)$ & $10(5.3 \%)$ & \\
\hline
\end{tabular}

* Data are presented as: mean \pm standard deviation $[\mathrm{SD}]$ and median (minimum $\div$ maximum); ${ }^{* *}$ Data presented as $\mathrm{N}(\%) ; \mathrm{X}-$ Chi2 Pearson test; $\mathrm{U}-$ Mann-Whitney test; $\mathrm{t}-\mathrm{Student}$ test ; $\mathrm{F}-$ Fisher Exact Test $\mathrm{BMI}$ - body mass index

Table 3. Questionnaire results. Data are presented as mean \pm standard deviation $[S D]$ and median (minimum $\div$ maximum)

\begin{tabular}{|c|c|c|c|c|}
\hline Parameter & $\begin{array}{l}\text { Women } \\
N=107\end{array}$ & $\begin{array}{c}\text { Men } \\
\mathbf{N}=93\end{array}$ & $\begin{array}{c}\text { All subjects } \\
\quad N=200\end{array}$ & $\begin{array}{c}\mathbf{p}^{\mathrm{u}} \\
\text { women vs men }\end{array}$ \\
\hline $\begin{array}{l}\text { Pain intensity } \\
\text { (VAS; 1-10) }\end{array}$ & $\begin{array}{l}6.13 \pm 2.09 \\
6.0(1 \div 10)\end{array}$ & $\begin{array}{l}5.90 \pm 2.20 \\
6.0(0 \div 10)\end{array}$ & $\begin{array}{l}6.02 \pm 2.14 \\
6.0(0 \div 10)\end{array}$ & $p=0.477$ \\
\hline $\begin{array}{l}\text { Quality of life } \\
\text { (EQ-5D; 5-15) }\end{array}$ & $\begin{array}{l}8.05 \pm 1.62 \\
8.0(5 \div 13)\end{array}$ & $\begin{array}{l}8.08 \pm 1.73 \\
8.0(5 \div 12)\end{array}$ & $\begin{array}{l}8.06 \pm 1.67 \\
8.0(5 \div 13)\end{array}$ & $p=0.891$ \\
\hline $\begin{array}{l}\text { Quality of life } \\
\text { (EQ-VAS; 1-100\%) }\end{array}$ & $\begin{array}{l}61.38 \pm 18.37 \\
60.0(5 \div 100)\end{array}$ & $\begin{array}{l}63.53 \pm 18.77 \\
70.0(10 \div 100)\end{array}$ & $\begin{array}{l}62.40 \pm 18.54 \\
70.0(5 \div 100)\end{array}$ & $p=0.413$ \\
\hline $\begin{array}{l}\text { Anxiety symptoms } \\
\text { (HADS-A;0-21) }\end{array}$ & $\begin{array}{l}6.87 \pm 3.99 \\
7.0(0 \div 19)\end{array}$ & $\begin{array}{l}5.82 \pm 3.99 \\
5.0(0 \div 17)\end{array}$ & $\begin{array}{l}6.38 \pm 4.01 \\
6.0(0 \div 19)\end{array}$ & $p=0.046$ \\
\hline $\begin{array}{l}\text { Depressive symptoms } \\
\text { (HADS-D; 0-21) }\end{array}$ & $\begin{array}{l}4.66 \pm 3.67 \\
5.0(0 \div 16)\end{array}$ & $\begin{array}{l}4.74 \pm 3.65 \\
5.0(0 \div 16)\end{array}$ & $\begin{array}{l}4.70 \pm 3.65 \\
4.0(0 \div 16)\end{array}$ & $p=0.849$ \\
\hline
\end{tabular}

U - U Mann-Whitney test; VAS - Visual Analogue Scale for intensity of pain; EQ-5D - EuroQol 5D quality of life self-esteem questionnaire; EQ-VAS - quality of life - visual analogue scale; HADS-A - Hospital Anxiety and Depression Scale — Anxiety Symptoms; HADS-D — Hospital Anxiety and Depression Scale — Depressive Symptoms 
Table 4. MRI scoring system. Data are presented as mean \pm standard deviation [SD] and median (minimum $\div$ maximum)

\begin{tabular}{|c|c|c|c|c|}
\hline & $\begin{array}{l}\text { Women } \\
N=107\end{array}$ & $\begin{array}{c}\text { Men } \\
\mathbf{N}=93\end{array}$ & $\begin{array}{c}\text { All subjects } \\
N=200\end{array}$ & $\begin{array}{c}\mathbf{p}^{\mathrm{u}} \\
\text { women vs men }\end{array}$ \\
\hline $\begin{array}{l}\text { Level L1-L2 } \\
\text { (points; 0-10) }\end{array}$ & $\begin{array}{c}0.42 \pm 1.06 \\
0.0(0 \div 5)\end{array}$ & $\begin{array}{c}0.94 \pm 1.76 \\
0.0(0 \div 7)\end{array}$ & $\begin{array}{c}0.66 \pm 1.45 \\
0.0(0 \div 7)\end{array}$ & $p=0.095$ \\
\hline $\begin{array}{l}\text { Level L2-L3 } \\
\text { (points; 0-10) }\end{array}$ & $\begin{array}{c}0.85 \pm 1.49 \\
0.0(0 \div 7)\end{array}$ & $\begin{array}{c}1.10 \pm 1.84 \\
0.0(0 \div 8)\end{array}$ & $\begin{array}{c}0.97 \pm 1.66 \\
0.0(0 \div 8)\end{array}$ & $p=0.471$ \\
\hline $\begin{array}{l}\text { Level L3-L4 } \\
\text { (points; 0-10) }\end{array}$ & $\begin{array}{c}1.64 \pm 1.98 \\
1.0(0 \div 8)\end{array}$ & $\begin{array}{c}2.48 \pm 2.27 \\
2.0(0 \div 8)\end{array}$ & $\begin{array}{c}2.03 \pm 2.16 \\
1.0(0 \div 8)\end{array}$ & $p=0.006$ \\
\hline $\begin{array}{l}\text { Level L4-L5 } \\
\text { (points; 0-10) }\end{array}$ & $\begin{array}{c}3.79 \pm 2.31 \\
4.0(0 \div 9)\end{array}$ & $\begin{array}{c}4.05 \pm 2.20 \\
4.0(0 \div 8)\end{array}$ & $\begin{array}{c}3.91 \pm 2.26 \\
4.0(0 \div 9)\end{array}$ & $p=0.371$ \\
\hline $\begin{array}{l}\text { Level L5-S1 } \\
\text { (points; 0-10) }\end{array}$ & $\begin{array}{c}3.80 \pm 2.92 \\
4.0(0 \div 9)\end{array}$ & $\begin{array}{c}4.42 \pm 2.22 \\
5.0(0 \div 9)\end{array}$ & $\begin{array}{c}4.09 \pm 2.63 \\
4.0(0 \div 9)\end{array}$ & $p=0.095$ \\
\hline $\begin{array}{l}\text { Total MRI score (from L1 to S1) } \\
\text { (points; } 0-50 \text { ) }\end{array}$ & $\begin{array}{l}10.47 \pm 6.46 \\
10.0(0 \div 30)\end{array}$ & $\begin{array}{l}12.88 \pm 6.83 \\
12.0(0 \div 34)\end{array}$ & $\begin{array}{l}11.59 \pm 6.73 \\
11.0(0 \div 34)\end{array}$ & $p=0.015$ \\
\hline
\end{tabular}

U - U Mann-Whitney test

Table 5. Prevalence of radiological findings in study group (from L1 to S1 levels)

\begin{tabular}{lc|} 
Radiological finding & Total number (percentage) \\
\hline Modic type 1 & $35(3.5 \%)$ \\
Modic type 2 & $89(8.9 \%)$ \\
Modic type 3 & $9(0.9 \%)$ \\
Pfirrmann grade 2 & $156(15.6 \%)$ \\
Pfirrmann grade 3 & $158(15.8 \%)$ \\
Pfirrmann grade 4 & $123(12.3 \%)$ \\
Pfirrmann grade 5 & $116(11.6 \%)$ \\
Annular tear & $112(11.2 \%)$ \\
Bulging & $259(25.9 \%)$ \\
Protrusion & $185(18.5 \%)$ \\
Extrusion & $64(6.4 \%)$ \\
Sequestration & $3(0.3 \%)$ \\
Nerve root compression & $103(10.3 \%)$ \\
Nerve root displacement & $198(19.8 \%)$ \\
\end{tabular}

U Mann-Whitney test). EQ-5D and EQ-VAS results were associated with the level of education ( $p=0.045$ and $p=0.004$, respectively; Kruskal-Wallis test) and the nature of work ( $\mathrm{p}<0.001$; U Mann-Whitney test) (self-esteemed quality of life was decreased in patients with lower education level and/or those who were manual workers). No association was found between MRI findings and the place of residence, education, socioeconomic status, marital status, nature of work or physical activity.
Table 6. Correlations between total MRI score and questionnaire results (Spearman's correlation)

\begin{tabular}{lc} 
& Total score \\
\hline Pain intensity & $\mathrm{R}=0.14$ \\
(VAS scale) & $\mathrm{p}=0.053$ \\
Quality of life & $\mathrm{R}=0.18$ \\
(EQ-5D) & $\mathrm{p}=0.012$ \\
Quality of life & $\mathrm{R}=-0.09$ \\
(EQ-VAS) & $\mathrm{p}=0.192$ \\
Anxiety symptoms & $\mathrm{R}=0.02$ \\
(HADS-A) & $\mathrm{p}=0.737$ \\
Depressive symptoms & $\mathrm{R}=0.21$ \\
(HADS-D) & $\mathrm{p}=0.003$
\end{tabular}

VAS - Visual Analogue Scale for intensity of pain; EQ-5D - EuroQol 5D quality of life self-esteem questionnaire; EQ-VAS - quality of life - visual analogue scale; HADS-A - Hospital Anxiety and Depression Scale — Anxiety Symptoms; HADS-D — Hospital Anxiety and Depression Scale — Depressive Symptoms

\section{Discussion}

Patients with LBP tend to have more radiological abnormalities on MRI scans, including disc degeneration, Modic type changes and herniations compared to controls without back pain [23]. Some previous studies of patients with LBP compared the sum of several MRI findings with clinical symptoms [11-13]. In the present study, we evaluated the association between total MRI changes of the LS (from L1 to S1) and pain intensity, quality of life, depressive and anxiety symptoms in patients with LBP. To the best of our knowledge, ours is the first study to investigate such relationships. 
In the study of Mariconda et al. [13], the total number of degenerative changes in the LS seen on MRI scans showed a borderline correlation with disability scores $(p=0.05)$ and pain duration $(\mathrm{p}=0.011)$. Each intervertebral disc space from L1-S1 was evaluated and the total degeneration score was calculated. On the other hand, Berg et al. [12] found no association between total MRI changes and the degree of disability or LBP intensity in candidates for lumbar disc prosthesis. The analysis evaluated the following: disc height decrease, Modic changes types I and II, HIZ and hypointense nucleus pulposus on L4-L5 and L5-S1 levels. Arana et al. [11] found a weak correlation between the combined MRI score and pain interference with work $(\mathrm{p}=0.04)$, but no correlation with the degree of disability while evaluating disc and facet findings, spinal stenosis and other pathologies in the two most affected LS levels on MRI scans.

Although those results are not comparable to ours due to different MRI variables, other clinical measurement methods, and different patient samples, our findings showed no correlation between pain symptoms and the total MRI score. We did not investigate the degree of disability. We found no relationship between physical activity and total MRI changes.

Unlike other studies $[11,12]$, we decided to increase the extent of the assessed spine levels from L1 to S1 and to extend the number of evaluated radiological findings. Because there is no validated measurement or scoring system to assess MRI scans of the LS, we decided to prepare our own scoring system related to selected degenerative MRI findings. This concept has already been used by other authors [12]. However, in this study we created a completely different MRI scoring system which contained changes most commonly observed in degenerative LS disease [24].

The main advantage of our study is related to the fact that it is the first research exploring the above-mentioned correlations. Furthermore, we assessed a relatively large patient group and extended MRI findings evaluated by radiologists. Moreover, the study included standardised nomenclature and classification systems that are currently used for the diagnosis of degenerative disease of the spine [24,25]. The MRI changes were classified according to a consensus reached between three radiologists. In our opinion, the total MRI score is an objective and measurable tool which represents the severity of degeneration of the LS. Furthermore, this study includes comprehensive assessments of pain intensity, depressive and anxiety syndromes and quality of life using validated instruments. Moreover, the neurological examination was conducted on the same day that the MRI examination was performed, and a detailed history provided wide clinical knowledge about the sample group.

We observed increasing morphological LS degeneration seen on MRI scans with increasing age and BMI, as was demonstrated by previous researches [13, 26]. We observed significantly more LS MRI changes in men compared to women, which is consistent with observations made by other authors $[13,27]$. Most of the radiological findings were seen on L4-L5 and L5-S1 levels, which is also consistent with other reports [11, 27]. Hollingworth et al. [27] found that $45 \%$ of patients with LBP and sciatica pain had no nerve root impingement on MRI. In our results only six patients with stretching sign had no nerve root changes. The explanation of such an enormous difference is probably related to a different method of assessing the symptoms i.e. medical history $v s$ neurological examination, which is more specific.

Our study confirmed previous observations related to the problem of decreased quality of life, depressive and anxiety symptoms in chronic pain syndromes [2]. Moreover, a relationship between physical and professional activity and clinical symptoms was observed. This finding suggested that reduced disability (e.g. due to physiotherapy) and a quick return to work are important in the management of patients with LBP; long sick leave is not recommended.

Our study confirmed a poor association between radiological findings and clinical symptoms. No relationship was observed between combined MRI findings and intensity of pain, depressive and anxiety syndrome or quality of life. We believe that these results are clinically relevant. Chou et al. [28] showed that immediate, routine LS imaging in patients with LBP with no features suggestive of serious underlying conditions (such as cancer, infection, cauda equina syndrome) did not improve clinical outcomes compared to usual clinical care without immediate imaging. Moreover, early MRI in acute LBP without indications provides no benefits and could result in worse outcomes such as 'iatrogenic' work disability and an unnecessary medical procedure [29]. Routine and immediate LS imaging in asymptomatic patients is not recommended and could result in worse outcomes [10, 28, 29]. The number of MRI examinations is still increasing, and this generates higher costs. On the other hand, patients expect advanced diagnostic imaging. We share the opinion of Chou et al. [28] that patient education is important in order to change the expectations of patients and avoid unnecessary examinations.

Lumbar spine pain syndrome is a complex psychological, physiological and behavioural problem. Despite numerous studies, management in LBP still remains a challenge for clinicians. Pain reduction is the priority in the therapeutic process. However, depressive and anxiety symptoms and poor quality of life need to be considered as well. Treatment of depression and anxiety may help in patients with chronic pain symptoms.

Our study is another step towards improving the understanding of the complexity of clinical-radiological correlations in LBP syndromes. Further studies are needed to improve management in LBP.

\section{Limitations of the study}

There are some limitations of our study. Firstly, we did not exclude patients with chronic diseases such as diabetes 
mellitus, heart failure, hypertension, skin diseases or allergies. These diseases can affect quality of life and increase psychological distress in patients. Secondly, the clinical features of the disease and symptoms may have changed while waiting for MRI, as the average duration from referral to MRI examination was $7.49 \pm 5.81$ months.

It is crucial to stress that there was no asymptomatic control group. However, our aim was not to compare two samples, rather we focused only on patients with LBP. The MRI scanning conditions were different (1.5T and 3T). However, this did not affect the results, as different magnetic field strengths do not change the assessment of radiological changes in degenerative spine disease.

\section{Conclusions}

Combined degenerative MRI changes in the LS do not correlate with LBP intensity, anxiety and depressive symptoms or quality of life. The total MRI findings are only associated with age and BMI.

Acknowledgements. The authors wish to thank Arkadiusz Badzinski, DHSc, Assistant Professor at the University of Silesia, authorised medical interpretator and translator, for language correction of this paper.

\section{References}

1. Dagenais S, Caro J, Haldeman S. A systematic review of low back pain cost of illness studies in the United States and internationally. Spine J. 2008; 8(1): 8-20, doi: 10.1016/j.spinee.2007.10.005, indexed in Pubmed: 18164449.

2. Pakpour AH, Nikoobakht M, Campbell P. Association of pain and depression in those with chronic low back pain: the mediation effect of patient sexual functioning. Clin J Pain. 2015; 31(1): 44-51, doi: 10.1097/AJP.0000000000000076, indexed in Pubmed: 25485954.

3. Bahouq $\mathrm{H}$, Allali F, Rkain $\mathrm{H}$, et al. Discussing sexual concerns with chronic low back pain patients: barriers and patients' expectations. Clin Rheumatol. 2013; 32(10): 1487-1492, doi: 10.1007/s10067013-2299-y, indexed in Pubmed: 23743660.

4. Beattie PF, Meyers SP, Stratford P, et al. Associations between patient report of symptoms and anatomic impairment visible on lumbar magnetic resonance imaging. Spine (Phila Pa 1976). 2000; 25(7): 819-828, indexed in Pubmed: 10751293.

5. Jarvik JG, Hollingworth W, Heagerty PJ, et al. Three-year incidence of low back pain in an initially asymptomatic cohort: clinical and imaging risk factors. Spine (Phila Pa 1976). 2005; 30(13): 1541-8; discussion 1549, indexed in Pubmed: 15990670.

6. Chung $\mathrm{CB}$, Vande Berg BC, Tavernier T, et al. End plate marrow changes in the asymptomatic lumbosacral spine: frequency, distribution and correlation with age and degenerative changes. Skeletal Radiol. 2004; 33(7): 399-404, doi: 10.1007/s00256-004-0780-z, indexed in Pubmed: 15138721.

7. Weishaupt D, Zanetti M, Hodler J, et al. MR imaging of the lumbar spine: prevalence of intervertebral disk extrusion and sequestration, nerve root compression, end plate abnormalities, and osteoarthri- tis of the facet joints in asymptomatic volunteers. Radiology. 1998; 209(3): 661-666, doi: 10.1148/radiology.209.3.9844656, indexed in Pubmed: 9844656.

8. Jensen OK, Nielsen CV, Sørensen JS, et al. Back pain was less explained than leg pain: a cross-sectional study using magnetic resonance imaging in low back pain patients with and without radiculopathy. BMC Musculoskelet Disord. 2015; 16: 374, doi: 10.1186/s12891-0150827-4, indexed in Pubmed: 26635015.

9. Endean A, Palmer KT, Coggon D. Potential of magnetic resonance imaging findings to refine case definition for mechanical low back pain in epidemiological studies: a systematic review. Spine (Phila Pa 1976). 2011; 36(2): 160-169, doi: 10.1097/BRS.0b013e3181cd9adb, indexed in Pubmed: 20739918.

10. Chou D, Samartzis D, Bellabarba C, et al. Degenerative magnetic resonance imaging changes in patients with chronic low back pain: a systematic review. Spine (Phila Pa 1976). 2011; 36(21 Suppl): S43S53, doi: 10.1097/BRS.0b013e31822ef700, indexed in Pubmed: 21952189.

11. Arana E, Martí-Bonmatí L, Vega M, et al. Relationship between low back pain, disability, MR imaging findings and health care provider. Skeletal Radiol. 2006; 35(9): 641-647, doi: 10.1007/s00256-0060100-x, indexed in Pubmed: 16602016.

12. Berg L, Hellum C, Gjertsen $\emptyset$, et al. Norwegian Spine Study Group. Do more MRI findings imply worse disability or more intense low back pain? A cross-sectional study of candidates for lumbar disc prosthesis. Skeletal Radiol. 2013; 42(11): 1593-1602, doi: 10.1007/s00256013-1700-x, indexed in Pubmed: 23982421.

13. Mariconda M, Galasso O, Imbimbo L, et al. Relationship between alterations of the lumbar spine, visualized with magnetic resonance imaging, and occupational variables. Eur Spine J. 2007; 16(2): 255-266, doi: 10.1007/s00586-005-0036-1, indexed in Pubmed: 16835739 .

14. Wewers ME, Lowe NK. A critical review of visual analogue scales in the measurement of clinical phenomena. Res Nurs Health. 1990; 13(4): 227-236, indexed in Pubmed: 2197679.

15. Zigmond AS, Snaith RP. The Hospital Anxiety and Depression Scale. Acta Psychiatrica Scandinavica. 1983; 67(6): 361-370, doi: 10.1111/j.1600-0447.1983.tb09716.x.

16. Sobczyk W, Gugała M, Rola R. Rozwój badań nad jakością życia w chorobach przewlekłych. Post Psychiatr Neurol. 2008; 17(4): 353-356.

17. Fardon DF, Milette PC. Combined Task Forces of the North American Spine Society, American Society of Spine Radiology, and American Society of Neuroradiology. Nomenclature and classification of lumbar disc pathology. Recommendations of the Combined task Forces of the North American Spine Society, American Society of Spine Radiology, and American Society of Neuroradiology. Spine (Phila Pa 1976). 2001; 26(5): E93-E9E113, indexed in Pubmed: 11242399.

18. Pfirrmann CW, Metzdorf A, Zanetti M, et al. Magnetic resonance classification of lumbar intervertebral disc degeneration. Spine (Phila Pa 1976). 2001; 26(17): 1873-1878, indexed in Pubmed: 11568697.

19. Modic MT, Masaryk TJ, Ross JS, et al. Imaging of degenerative disk disease. Radiology. 1988; 168(1): 177-186, doi: 10.1148/radiology.168.1.3289089, indexed in Pubmed: 3289089.

20. Rahme R, Moussa R. The modic vertebral endplate and marrow changes: pathologic significance and relation to low back pain and segmental instability of the lumbar spine. AJNR Am J Neuroradiol. 2008; 29(5): 838-842, doi: 10.3174/ajnr.A0925, indexed in Pubmed: 18272564. 
21. Albert HB, Manniche C. Modic changes following lumbar disc herniation. Eur Spine J. 2007; 16(7): 977-982, doi: 10.1007/s00586-0070336-8, indexed in Pubmed: 17334791.

22. Kuisma M, Karppinen J, Niinimäki J, et al. Modic changes in endplates of lumbar vertebral bodies: prevalence and association with low back and sciatic pain among middle-aged male workers. Spine (Phila Pa 1976). 2007; 32(10): 1116-1122, doi: 10.1097/01. brs.0000261561.12944.ff, indexed in Pubmed: 17471095.

23. Hancock M, Maher C, Macaskill P, et al. MRI findings are more common in selected patients with acute low back pain than controls? European Spine Journal. 2011; 21(2): 240-246, doi: 10.1007/s00586-011-1955-7.

24. Heuck A, Glaser C. Basic aspects in MR imaging of degenerative lumbar disk disease. Semin Musculoskelet Radiol. 2014; 18(3): 228 239, doi: 10.1055/s-0034-1375566, indexed in Pubmed: 24896740.

25. Waldt S, Gersing A, Brügel M. Measurements and classifications in spine imaging. Semin Musculoskelet Radiol. 2014; 18(3): 219-227, doi: 10.1055/s-0034-1375565, indexed in Pubmed: 24896739.
26. Liuke M, Solovieva S, Lamminen A, et al. Disc degeneration of the lumbar spine in relation to overweight. Int J Obes (Lond). 2005; 29(8): 903-908, doi: 10.1038/sj.ijo.0802974, indexed in Pubmed: 15917859.

27. Hollingworth W, Dixon AK, Todd CJ, et al. Self reported health status and magnetic resonance imaging findings in patients with low back pain. Eur Spine J. 1998; 7(5): 369-375, indexed in Pubmed: 9840469.

28. Chou R, Fu R, Carrino JA, et al. Imaging strategies for low-back pain: systematic review and meta-analysis. Lancet. 2009; 373(9662): 463472, doi: 10.1016/S0140-6736(09)60172-0, indexed in Pubmed: 19200918.

29. Webster BS, Bauer AZ, Choi Y, et al. latrogenic consequences of early magnetic resonance imaging in acute, work-related, disabling low back pain. Spine (Phila Pa 1976). 2013; 38(22): 1939-1946 doi: 10.1097/BRS.0b013e3182a42eb6, indexed in Pubmed: 23883826. 